\title{
Computer-mediated instruction: a comparison of online and face-to-face collaboration
}

\author{
Jeremy I. Tutty · James D. Klein
}

Published online: 15 April 2008

(C) Association for Educational Communications and Technology 2008

\section{Erratum to: Education Tech Research Dev DOI 10.1007/s11423-007-9050-9}

The following reference was omitted from the above-referenced paper, published in volume 56, number 2.

Pollard, C., VanDehey, T., \& Pollard, R. (2003). Curricular computing: essential skills for teachers. Boise, ID: Boise State University Printing.

This reference should also be cited in the following places within the text of the article:

Page 106, Paragraph One, First Sentence: should read:

"A CBI module on the basic functions of Microsoft Excel ${ }^{\mathrm{TM}}$ and the application of spreadsheets in the classroom, adapted from Pollard et al. (2003) was developed for this study by the first author using Macromedia Director."

Page 107, Paragraph Two, Fifth Sentence, should read:

"The following is the problem scenario that was provided to students (Pollard et al. 2003, pp. 159-160):"

The online version of the original article can be found under doi:10.1007/s11423-007-9050-9.

J. I. Tutty $(\bowtie)$

Boise State Univeristy, 1910 University Drive, Boise, ID 83725-1747, USA

e-mail: jtutty@boisestate.edu

J. D. Klein

Division of Psychology in Education, Arizona State University - Tempe, Tempe, AZ 85287-0611,

USA

e-mail: james.klein@asu.edu 